\title{
A Study on the Cultivation Mode of Innovative Talents in Rehabilitation Therapeutics Specialty in Aging Society
}

\author{
Gu Yanchun a , Zhao Chunshan ${ }^{\mathrm{b}, *}$ \\ School of BeiHua University, Jilin 132013, China

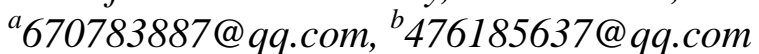

Keywords: population ageing; rehabilitation therapeutics; talent cultivation; mode

Abstract: With the arrival of the aging population society in China, accordingly the demographic structure of our country has also changed, which has a great influence on our country's medical security system, especially in the medical care, the old-age care and other systems. In order to meet the requirements of social development, train a large number of rehabilitation therapeutics talents for the society, this paper analyzes and optimizes the talents cultivation measures as well as modes concerning the major of the rehabilitation therapeutics in details, hoping it is helpful to the cultivation of the talents specialized in the rehabilitation therapeutics.

\section{Introduction}

Rehabilitation therapeutics is a new branch of medicine that emerged in the late 1950s. Rehabilitation is aimed at people, as an applied medical discipline, its main task is to reduce the patient's dysfunction while enable patients to readjust to normal life. In recent years, with the increasing incidence of cardiovascular diseases, malignant tumors and other diseases, it has increased the burden on the society as well as the family for medical care and the old-age care. Although our country's rehabilitation cause has developed to a certain extent under the efforts of the state, however, because our country has a large population, the aging population is also relatively large, which also brings new challenges to the cause of the old-age rehabilitation in our country.

\section{Development Trend of Rehabilitation Therapeutics}

When the proportion of the population over the age of 65 exceeds $7 \%$ of the total population, it can be called "aging society", and when it exceeds $14 \%$, it can be called "the society of the aged". The problem of the aging of the population has received a lot of attention. China's aging population had reached $7.6 \%$ in 2005 . The aging of the population will not only affect the economic development, but also have an important impact on medical services. Some advanced countries have reached a certain stage of the corresponding economic and material development in an aging society, so they have sufficient funds to solve these problems. However, China is different from the above situation, China does not have enough funds to solve this problem in the early stage of aging.

In order to improve the quality of the life of the elderly with these diseases, it is imperative to accelerate the training of the rehabilitation therapeutics professional talents. Through the study, we 
found that the exercise of the effective rehabilitation treatment could make the majority of the patients get the ability to walk and self-care in daily life, while a small number of patients could get back to work. If it failed to undertake the rehabilitation treatment, very few patients can restore the ability to walk and self-care in daily life. In recent years, the incidence of myocardial infarction, cerebral vascular disorders, cancer and other diseases in China has been increasing, which has also brought great challenges to China's rehabilitation medicine. The population base of our country is large, the elderly population is more, at the same time, influenced by Chinese traditional culture, most of the family in our country adopts the mode of the household care of the elderly, as a result, the way of the community support for the old should be actively promoted in China, under the circumstances, the effective combination of the community support for the elderly with the community rehabilitation is the development direction of rehabilitation medicine in our country in the future.

\section{Current Situation of Cultivating the Rehabilitation Therapeutics Professional Talents}

Rehabilitation therapeutics is an important part of modern medicine, which is different from the traditional biomedical model. Therefore, rehabilitation medical workers should not only have the knowledge of biomedical science, but also have relatively high practical ability. This discipline is a subject that is demanding in practice, but most teachers still use the traditional teaching methods, and there is little communication between teachers and students, which can not improve students' learning enthusiasm. With the development of economy in our country, this kind of teaching method can no longer be satisfied with the needs of the development of society, the traditional teaching method pays more attention to cultivate students' theoretical knowledge level, ignoring the students' practice ability, therefore, the corresponding adaptability is relatively low. Although the education of rehabilitation therapeutics has got the certain development in China, but it still exists some problems, such as it could not well match with the social needs in the following aspects: the teaching methods, curriculum system, training mode, etc. It has the necessity to make further improvement as well as adjustment in order to meet the practical need of society.

\section{Cultivation Mode of Rehabilitation Therapeutics Professional Talents under the Background of Aging Population}

\subsection{Determine the Talent Cultivation Goal}

The goal of talent training is of great significance to the advanced education, at the same time, it is the important basis for the institutions for the advanced education to determine the educational system, curriculum system and teaching content. The cultivation objectives of rehabilitation therapeutics major should be the training of such a kind of medical talents for the society that they has the basic knowledge of Chinese and western medicine, the professional knowledge of rehabilitation therapeutics, professional skills as well as good professional quality, innovation spirit and practice ability, while they can be engaged in rehabilitation treatment work in hospital at all levels, social rehabilitation institutions and so on.

\subsection{Improve the Course Mechanism}

The professional courses of rehabilitation therapeutics mainly include the following four modules: education course of general knowledge, professional basic course, professional course and clinical practice. Discipline basic course contains the functional anatomy, kinesiology, physiology, diagnostics and so on, which attaches great importance to the teaching of the nervous system and 
motor system, accordingly ensure the professional course learning laying a corresponding solid basic medical knowledge. In addition, the humanities courses such as medical ethics, medical psychology and interpersonal communication have been arranged to effectively improve students' communication ability. In the professional curriculum, the contents such as neurology and the science of rehabilitation function assessment, language therapy science, etc. have been set up, at the same time, it also sets up the courses of traditional Chinese medicine, Chinese medicine health preservation, etc., which could make the students learn traditional Chinese medicine rehabilitation therapy.

\subsection{Adjustment of Teaching Resources}

Make full use of the school's teaching resources as well as various practice teaching bases and other resources to create good teaching conditions for basic courses and specialized courses concerning the rehabilitation therapeutics major. Practice teaching can effectively improve teaching quality. It will increase investment in laboratories and training bases, improve experimental conditions, increase experimental equipment, and create a good practice environment for students majoring in rehabilitation treatment, to ensure that the requirements of teaching activities are met. Professional courses should be taken charge of by practice teaching bases, which can effectively improve students' practice ability, train a large number of rehabilitation therapeutics professional talents for the society.

\subsection{Optimize Classroom Teaching and Practice}

Theoretical courses will be divided into required courses and restricted courses, meanwhile, they are divided into core contents, important contents as well as general contents. Teachers focus on teaching students the core content, which students must master. The important content is an extension of the core content and it requires students be familiar with it. The teacher uses the way of guidance as well as answering the related questions and so on to teach the general content for the students, accordingly the student must understand the content of this aspect. When teaching theoretical courses, teachers apply the problem-centered teaching mode in class. Students can be divided into several groups for discussion, such as the discussion group of "discussion concerning the rehabilitation issue", "geriatric diseases research". In addition, extra-curricular activities can be adopted to guide students to learn by focusing on the problems and improve their ability of independent learning.

\subsection{Optimize Practice Teaching}

Rehabilitation therapeutics is the subject that is demanding in practice, accordingly the students should have higher practice ability and innovation capability, therefore, the teacher emphasizes the cultivation of the students' ability, meanwhile, a diversified practice teaching system has been established. According to the nature of the courses, the proportion of theoretical courses and practice courses in school hours is formulated. At present, the undergraduate practice courses of rehabilitation therapeutics major in our college account for $40 \%$ of the total courses. Through the practice teaching method of "early contact, more contact", let students participate in the practice activities related to rehabilitation treatment as soon as possible, improve their understanding of rehabilitation treatment, which has completed the seamless connection with the clinical practice after graduation. It has improved the students' practice ability, observation and problem-solving ability, clinical thinking capability and professional competence to a large extent, which has realized the training of the application-oriented rehabilitation talents who can meet social needs. 
In a word, with the arrival of China's aging society, rehabilitation medicine also faces new challenges. At present, the quantity of the rehabilitation hospital is less, meanwhile, the rehabilitation professional talents is less, as a result, there is the necessity to adjust the pattern of cultivating the rehabilitation professional talents, so as to cultivate a large number of rehabilitation professionals for the society. Use the new training mode that can meet the need of social development, combine the old-age care with rehabilitation, attach great importance to the teaching of the rehabilitation the elderly chronic disease, improve the students' practice ability, so as to promote the healthy development of the rehabilitation therapeutics major, cultivate the high-quality as well as high-level talents of rehabilitation treatment for society.

\section{Acknowledgements}

This work was financially supported by Teaching Reform of Occupational Education and Adult Education of the Education Department of Jilin Province in 2017 (2017zcy113); The Periodic Research Results of the Teaching Reform Project of the Education Department of Jilin Province in 2017 (SJJY201709). The corresponding author is Zhao Chunshan, Female, (1980-), Doctor's degree.

\section{References}

[1] Jiang Xifu, Zhou Qinying, Yang Chunxiang, et al. Thoughts on the Cultivation of Talents in the Healthy Old-age Care Industry in the Context of Population Aging [J]. Journal of Chizhou College, 2015, 29(2):142-144.

[2] Zhang Xinbo, Zhang Hongwei, Chen Feng, et al. Discussion on the Education Status of Rehabilitation Medicine Major in Chinese Advanced Universities [J]. Health Care Guide: Medical Research, 2015(12):23-23.

[3] Tong Zhaoyan, Wang Yun, Li Yong, et al. Investigation and Research on the Training of Rehabilitation Professional Talents in the Advanced Colleges and Universities of Traditional Chinese Medicine [J]. Journal of Chengdu University of Traditional Chinese Medicine (Education Scientific Edition), 2016(2):14-16. 